\title{
中印度洋与南海西部表层海水细菌多样性
}

\author{
夏呈强@1\#，李毅 $2,3 \#^{*} ，$ 党延茹 ${ }^{3}$, 察倩倩 $^{3}$, 贺晓艳 ${ }^{3}$, 秦启龙 ${ }^{3}$
}

1. 山西农业大学动物科学学院, 山西太谷 $030801 ; 2$. 山西农业大学生命科学学院, 山西太谷 $030801 ; 3$. 山东大学微生物技术国家重点实 验室, 山东青岛 266237

摘要: 细菌在海洋生物地球化学循环中发挥着重要作用。为更好地了解海洋细菌的特征及其在海洋环境中的潜在作用, 本文 利用纯培养与16S rRNA基因高通量测序技术对中印度洋与南海西部海域表层海水细菌多样性进行研究。纯培养结果表明, 自 中印度洋与南海西部表层海水中共分离 275 株可培养海洋细菌, 隶属于4门49属75种。变形菌门是绝对优势类群(占总株数的 $68.7 \%)$, 其次是放线菌门 $(21.5 \%)$ 、拟杆菌门 $(9.1 \%)$ 和厚壁菌门 $(0.7 \%)$ 。在属水平, 微杆菌属(Microbacterium)与弧菌属(Vibrio) 是主要的优势属, 共占总株数的 $30.0 \%$ 。在 3 种分离培养基中, 自 $1 / 10 \times 2216 \mathrm{E}$ 培养基中分离细菌的数目与种类最多 $(89$ 株, 30 属); 分离菌株中的细菌菌株有7、9与 3 个属分别仅在 $2216 \mathrm{E} 、 1 / 10 \times 2216 \mathrm{E}$ 及葡萄糖甘露糖(glucose-mannose, GM)培养基中生 长。此外, 共分离培养出 50 株细菌(26种)可能代表潜在新分类单元。高通量测序结果显示, 中印度洋和南海西部表层海水中 共有 23 个门 531 个属。优势门类为变形菌门(72.2\%)和拟杆菌门(15.3\%), 优势属为嗜冷杆菌属(Psychrobacter, 24.4\%)、盐单胞 菌属(Halomonas, 16.3\%)和亚硫酸杆菌属(Sulfitobacter, 13.9\%)。此外, 中印度洋表层海水细菌Shannon-Wiener指数与Pielou均 匀度指数显著高于南海西部 $(P<0.05)$, 且细菌群落结构显著不同 $(P<0.05)$ 。综合纯培养与原位细菌数据得出, 中印度洋与南 海西部海洋细菌具有丰富的多样性, 具有进一步开发研究的价值。

关键词: 中印度洋; 南海西部; 表层海水; 高通量测序; 细菌多样性

夏呈强, 李毅, 党延茹, 察倩倩, 贺晓艳, 秦启龙 (2022) 中印度洋与南海西部表层海水细菌多样性. 生物多样性, 30, 21407. doi: 10.17520/biods.2021407.

Xia CQ, Li Y, Dang YR, Cha QQ, He XY, Qin QL (2022) Diversity of culturable and in situ bacteria in surface seawater from the central Indian Ocean and the western South China Sea. Biodiversity Science, 30, 21407. doi: 10.17520/biods.2021407.

\section{Diversity of culturable and in situ bacteria in surface seawater from the central Indian Ocean and the western South China Sea}

Chengqiang Xia ${ }^{\circledR 1 \#}$, Yi Li ${ }^{2,33^{*}}$, Yanru Dang ${ }^{3}$, Qianqian $\mathrm{Cha}^{3}$, Xiaoyan $\mathrm{He}^{3}$, Qilong Qin ${ }^{3}$

1 College of Animal Science, Shanxi Agricultural University, Taigu, Shanxi 030801

2 College of Life Sciences, Shanxi Agricultural University, Taigu, Shanxi 030801

3 State Key Laboratory of Microbial Technology, Shandong University, Qingdao, Shandong 266237

\section{ABSTRACT}

Aims: Bacteria play an important role in driving biogeochemical cycling in the open ocean. Therefore, it is of great significance to investigate the characteristics of marine bacteria and their potential role in the marine environment.

Methods: In this study, surface seawater was collected from 8 sites in the central Indian Ocean and the western South China Sea. Three different media were utilized for strains isolation and identification, and the 16S rRNA gene high-throughput sequencing method was used to analyze the microbial classification and community composition of each study site.

Results: A total of 275 strains, belonging to 4 phyla, 49 genera and 75 species, were isolated and identified. Proteobacteria were the most dominant, accounting for $68.7 \%$ of the total isolates, followed by Actinobacteria (21.5\%), Bacteroidetes (9.1\%) and Firmicutes (0.7\%). At the genus level, Microbacterium and Vibrio were the dominant genera,

收稿日期: 2021-10-11; 接受日期: 2021-10-20

基金项目：山西省优秀博士来晋工作奖励项目(SXYBKY2019024)、山西农业大学科技创新基金项目(2020BQ07)和国家自然科学基金(31870101)

\# 共同第一作者 Co-first authors

* 通讯作者 Author for correspondence. E-mail: liyi@sxau.edu.cn 
accounting for $30.0 \%$ of the total number of isolates. Bacterial abundance and species ( 89 isolates, 30 genera) in the $1 / 10 \times 2216 \mathrm{E}$ medium were the highest among the three kinds of media. Seven, nine and three genera were only found in 2216E, 1/10 × 2216E and glucose-mannose (GM) medium, respectively. Fifty strains (26 species) were identified as potential novel taxa. The sequencing analysis revealed that 23 phyla and 531 genera were found in the surface seawater. Dominant phyla were Proteobacteria (72.2\%) and Bacteroidetes (15.3\%), dominant genera were Psychrobacter (24.4\%), Halomonas (16.3\%), and Sulfitobacter (13.9\%). In addition, the Shannon-Wiener index and Pielou's evenness index were significantly higher in the Indian Ocean than the South China Sea $(P<0.05)$, and bacterial community structure was significantly different between those two regions $(P<0.05)$.

Conclusion: The results indicated that marine bacteria from the surface seawater of central Indian Ocean and western South China Sea were rich in diversity, and help the most value for further development and research.

Key words: central Indian Ocean; western South China Sea; surface seawater; high throughput sequencing; bacterial diversity

海洋是地球上最大的水生生态系统, 占据了地 球总表面积的 $71 \%$ 。广阔的表层海水经常表现出不 同的物理海洋过程, 如季风驱动的环流, 可造成营 养物质大规模的水平运输 $(\mathrm{Qu}$ et al, 2006; Wang et al, 2017)。在洋流的驱动下, 体积小、扩散能力强的微 生物可散布到世界海洋的每个角落(Salazar et al, 2016)。这些微生物是海洋生态系统中养分循环和能 量流动的主要承担者(Liu et al, 2014a)。选择性过程 包括环境压力(例如风、日光和养分的可利用性)和 生物相互作用(例如藻华和病毒裂解)可影响海洋微 生物群落的分布格局(Hanson et al, 2012; Bryant et al, 2016)。近年来, 16S rRNA基因高通量与宏基因组 测序技术的发展极大地推动了人类对全球海洋微 生物群落结构与功能的研究。与陆地微生物相比, 海洋微生物在物种类群、生理代谢特性与产物等方 面都存在着丰富的新颖性和多样性(Zhuang et al, 2020)。然而, 非培养技术并不能准确反映微生物的 生理生化特征与生态功能, 更重要的是无法获得并 利用这些微生物资源。

借助于可培养方法获得的微生物可以作为物 种库与功能基因库, 并对其进行资源开发和应用。 由于在实验条件下无法完全模拟海洋的环境条件, 目前只有不到 $1 \%$ 的海洋微生物可利用培养方法获 得(Rappé \& Giovannoni, 2003), 大量具有应用价值 的海洋微生物资源被埋没。迄今关于开阔大洋中可 培养微生物的研究大多集中在沉积物环境中(Yu et al, 2015; Su et al, 2020; Lin et al, 2021), 对水体中可 培养微生物的研究报道相对较少 (Zhuang et al, 2020), 特别是在不同实验条件下(如不同培养基、 不同海域等)对海洋微生物的规模化分离培养的研 究更是罕见(Lin et al, 2021)。因此, 结合可培养方法
与高通量测序技术对海洋微生物群落进行研究, 不 但能够有效挖掘微生物资源, 还有助于对海洋微生 物多样性有更加清晰的认识。

本研究从中印度洋及中国南海(以下简称南海) 西部采集 8 个站位的表层海水, 采用 3 种不同的培养 基进行规模化分离培养, 结合 $16 \mathrm{~S}$ rRNA基因高通 量测序技术探究细菌群落组成和多样性分布规律, 为揭示开阔海域水生微生物的生命过程及其生态 功能提供独特的微生物资源库。

\section{材料与方法}

\section{1 样品采集}

本研究所用表层海水(2-5 m) 样品均由“大洋一 号”科考船船载CTD采集。2014年1月, 在中国大洋 第30航次科考期间采集印度洋表层水(IO_1)。2016 年6-7月, 在中国大洋第39航次科考期间选取7个站 位采集印度洋(IO_14，IO_20)与南海西部(SCS_4, SCS_6, SCS_7, SCS_8, SCS_9)表层水(附录1), 具体 站位信息如表1所示。少量新鲜水样直接用于现场 平板涂布; $5 \mathrm{~L}$ 海水样品经 $0.22 \mu \mathrm{m}$ 滤膜过滤, 并将 滤膜放入无菌离心管, 置于 $-80^{\circ} \mathrm{C}$ 冰箱冷冻保存, 用于后续的高通量测序分析。

\section{2 培养基}

采用3种培养基, 分别为 $2216 \mathrm{E}(\mathrm{BD}$, 美国)、稀 释 10 倍 $2216 \mathrm{E}(1 / 10 \times 2216 \mathrm{E})$ 及葡萄糖甘露糖培养 基(glucose-mannose, GM) (成分：0.25\%葡萄糖、 $0.25 \%$ 甘露糖及 $0.2 \%$ 硝酸铵) 对海洋细菌进行分离 培养。

\section{3 纯培养菌株的分离纯化}

每个位点分别取两个梯度 $(50 \mu \mathrm{L}$ 和 $300 \mu \mathrm{L})$ 的 新鲜表层海水样品, 用一次性无菌涂布棒分别涂布 
至2216E、1/10 × 2216E和GM固体培养基上，每种 培养基每个梯度设置 2 个平行, 置于 $10^{\circ} \mathrm{C}$ 培养箱进 行培养。培养时间为 1-2个月(航行期间), 回实验室 后挑取不同形态和颜色的单菌落, 采用连续划线法 接种于 $2216 \mathrm{E}$ 培养基上进行反复分离纯化。

\section{4 纯培养菌株16S rRNA基因鉴定与系统发育分 析}

使用细菌基因组DNA快速提取试剂盒(百泰克, 中国)提取各个菌株的基因组。以提取的基因组为 模板, 利用通用引物 $27 \mathrm{~F}$ (5'-AGAGTTTGATCCTG GCTCAG-3') 和1492R (5'-TACGGTTACCTTGTTA CGACTT-3')进行细菌16S rDNA扩增。PCR扩增体 系和反应条件参照 $\mathrm{Du}$ 等(2019)的方法。PCR产物送 至济南博尚生物技术有限公司进行测序。

将获得的 $16 \mathrm{~S}$ rRNA 基因序列提交至 EzBioCloud (http://www.ezbiocloud.net/)进行Blast比 对, 得到菌株相似的种属及相似度信息, 并初步确 定其分类地位。将篮选的275株细菌的16S rRNA基 因序列进行 muscle 比对, 采用 MEGA 7 邻近法 (neighbor-joining algorithm)构建系统发育树, 并使 用在线网站EvolView (http://www. evolgenius.info/e olview/)编辑进化树。

\section{5 原位细菌群落的DNA提取及高通量测序}

$5 \mathrm{~L}$ 海水样品经 $0.22 \mu \mathrm{m}$ 滤膜过滤后, 滤膜放入 无菌离心管中, 液氮速冻后, 置于 $-80^{\circ} \mathrm{C}$ 保存。利用 PowerWater ${ }^{\circledR}$ DNA提取试剂盒提取滤膜菌体总DN A, 利用Nano-100微量分光光度计测定DNA浓度及 纯度, 同时通过琼脂糖凝胶电泳检测DNA提取效 果。以提取的总DNA为模板, 使用引物 $338 \mathrm{~F}$ (5'-AC TCCTACGGGAGGCAGCA-3') 和806R (5'-GGACT ACHVGGGTWTCTAAT-3')扩增细菌16S rRNA基 因的V3-V4区。扩增体系与反应条件参考 $\mathrm{Li}$ 等(201 $8)$ 的方法。

根据Illumina MiSeq PE300测序平台的标准流 程进行双端测序。利用QIIME2软件对获得的reads 进行去接头、质量控制及去重复, 并基于DADA2的 聚类分析获得ASV (amplicon sequence variants)表 和代表序列(Caporaso et al, 2010)。利用Silva数据库 (SSU132)对每条序列进行物种分类注释。

\section{6 数据分析}

使用QIIME2软件计算Faith系统发育多样性指
数, 使用Primer 6软件计算Margalef丰富度指数、 Pielou 均匀度指数、Shannon-Wiener 指数和 Bray-Curtis相似性。ANOSIM分析( $R$ 用于表征不同 组间的差异性; $P$ 用于表征显著差异性)和Cluster聚 类分析用于比较不同海域细菌群落组成差异 (Gauch \& Scruggs, 1980; Clarke, 1993; Keylock, 2005)。使用R软件进行Kruskal-Wallis检验和绘制堆 积图与弦状图(R Core Team, 2016)。

\section{2 结果}

\section{1 表层海水可培养海洋细菌多样性}

本研究共获得 275 株海洋细菌, 隶属于4门6纲 16目32科49属75种(图1, 附录2)。变形菌门(189株)、 放线菌门(59株)、拟杆菌门(25株)和厚壁菌门(2株) 分别占总分离菌株的 $68.7 \% 、 21.5 \% 、 9.1 \%$ 和 $0.7 \%$ (图1A)。在纲水平， $\alpha$-变形菌纲(134株)占绝对优势, 占总菌株数的 $48.7 \%$; 其次为放线菌纲 (59 株; $21.5 \%) 、 \gamma$-变形菌纲(55株; $20.0 \%)$ 和黄杆菌纲(22株; $8.0 \%$ ); 另外 2 个纲, 噬纤维菌纲包含3株, 芽狍杆菌 纲仅包含 2 株 (图 1B)。在属水平, 微杆菌属 (Microbacterium) 菌株最多, 共分离出55株, 占细菌 分离总数的 $20.0 \%$ (图2, 附录2)。弧菌属(Vibrio)为第 二大优势属, 占细菌分离总数的 $10.0 \%$ 。海茎状菌属 (Maricaulis)和赤杆菌属(Erythrobacter) 获得的菌株 数目分别为 19 株和 17 株。希瓦氏菌属(Shewanella) 和海洋柄菌属(Oceanicaulis)在内的18个属, 每属仅 分离培养出 1 株。

比较不同海域分离的细菌类群发现, 中印度洋 共获得菌株115株(27属), 南海西部共获得160株(38 属) (图2, 附录3)。其中, 11 个属的物种仅在中印度 洋海域分离得到, 22 个属的物种仅在南海西部地区 分离得到, 16 个属的物种在这两个海域都能分离得 到(附录3)。这些共有类群包括微杆菌属、弧菌属与 海茎状菌属等高丰度类群以及交替单胞菌属 (Alteromonas)、德沃斯式菌属(Devosia)、生丝单胞 菌属(Hyphomonas)、鼠尾菌属(Muricauda)、海洋柄 菌属 (Ponticaulis) 、假交替单胞菌属 (Pseudoalteromonas)、Thalassospira、玫瑰变色菌属 (Roseovarius)与玫瑰色菌属(Roseibium)等低丰度类 群(图2)。以上研究结果表明, 中印度洋及南海西部 广阔海域可培养细菌具有丰富的多样性。 


\section{2 不同培养基获得的海洋细菌多样性}

利用 3 种培养基对表层海水中海洋细菌进行 分离培养发现, 2216E中获得 81 株细菌 (27属), $1 / 10 \times 2216 \mathrm{E}$ 获得 89 株(30属), GM培养基获得 52 株(17属) (图3)。在纲水平, $\alpha$-变形菌纲、 $\gamma$-变形菌 纲和放线菌纲的细菌在3种培养基均能分离得到。 其中, $\alpha$-变形菌纲占绝对优势, 且在 $1 / 10 \times 2216 \mathrm{E}$ 培养基上占比最高 $(66.3 \%)$ 。与其他 2 种培养基相 比, GM培养基中缺少黄杆菌纲和噬纤维菌纲的 细菌, 但可获得芽孢杆菌纲细菌。在属水平, $2216 \mathrm{E} 、 1 / 10 \times 2216 \mathrm{E}$ 及 $\mathrm{GM}$ 培养基均获得 11 个属
的细菌, 其中, 微杆菌属在3种培养基中菌株数 目均最多(图3A)。作为第二大优势类群, 海茎状 菌属在 $1 / 10 \times 2216 \mathrm{E}$ 培养基中菌株数目相对较多。 鼠尾菌属与短小杆菌属(Brachybacterium)仅在不 同营养梯度2216E培养基中分离得到。此外，分别 有7、9 与 3 个属的细菌仅在 $2216 \mathrm{E} 、 1 / 10 \times 2216 \mathrm{E}$ 及 GM培养基中被培养(图3B)。

本研究共分离培养出50株潜在新分类单元, 分属于 26 个物种 $(16 \mathrm{~S} \mathrm{rRNA}$ 基因相似度低于 $98.65 \%$ ) (附录4)。其中, $2216 \mathrm{E}$ 中分离出 17 株潜在 新分类单元，分属于 10 个物种，疑似新种率为
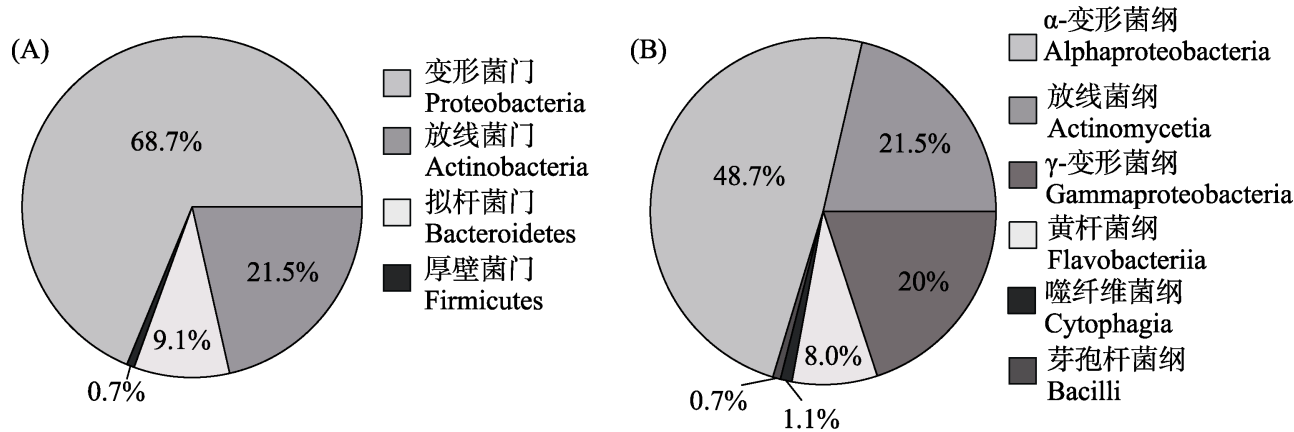

图 1 表层海水可培养细菌在(A)门和(B)纲水平的组成分布

Fig. 1 Distributions of cultivable bacteria at (A) phylum and (B) class level from different surface seawaters

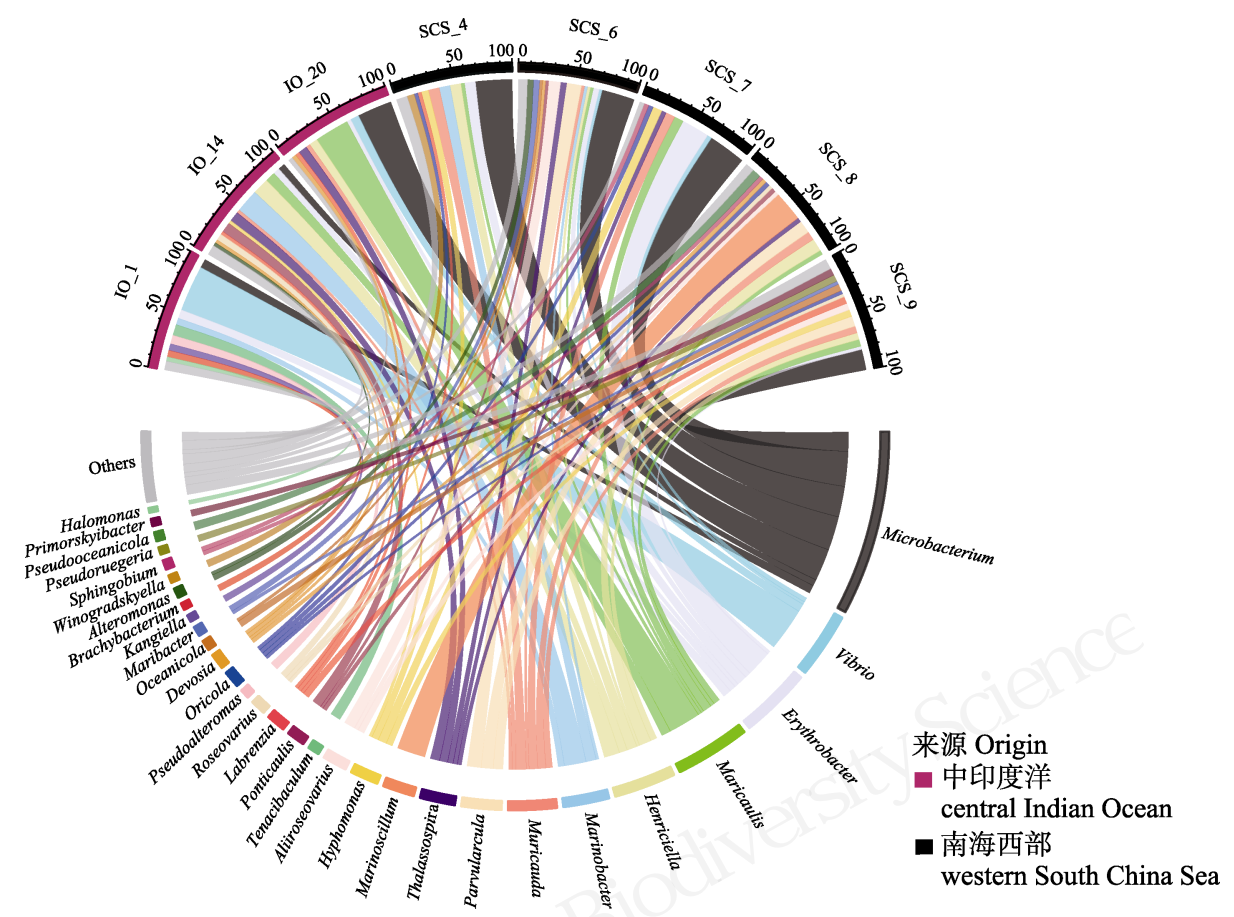

图 2 表层海水可培养细菌属的多样性

Fig. 2 Cultivable bacterial diversity of genus isolated from surface seawaters 
表 1 中印度洋与南海西部采样位点信息及非培养细菌群落生物多样性指数

Table 1 The information of sampling stations of the central Indian Ocean and the western South China Sea and biodiversity indices of uncultured bacterial communities

\begin{tabular}{|c|c|c|c|c|c|c|c|c|}
\hline $\begin{array}{l}\text { 站位 } \\
\text { Station }\end{array}$ & $\begin{array}{l}\text { 经度 } \\
\text { Longitude }\end{array}$ & $\begin{array}{l}\text { 纬度 } \\
\text { Latitude }\end{array}$ & $\begin{array}{l}\text { 温度 } \\
\text { Temperature } \\
\left({ }^{\circ} \mathrm{C}\right)\end{array}$ & OTU & $\begin{array}{l}\text { Margalef丰富度指数 } \\
\text { Margalef's richness } \\
\text { index }\end{array}$ & $\begin{array}{l}\text { Pielou均匀度指数 } \\
\text { Pielou's evenness } \\
\text { index }\end{array}$ & $\begin{array}{l}\text { Faith系统发育多 } \\
\text { 样性指数 } \\
\text { Faith's PD index }\end{array}$ & $\begin{array}{l}\text { Shannon-Wiener指数 } \\
\text { Shannon-Wiener } \\
\text { index }\end{array}$ \\
\hline IO_1 & $51.30^{\circ} \mathrm{E}$ & $36.93^{\circ} \mathrm{S}$ & 19.8 & 519 & 45.15 & 0.75 & 32.00 & 6.77 \\
\hline IO_14 & $85.36^{\circ} \mathrm{E}$ & $19.52^{\circ} \mathrm{S}$ & 25.4 & 354 & 30.77 & 0.59 & 29.17 & 4.99 \\
\hline IO_20 & $96.62^{\circ} \mathrm{E}$ & $11.29^{\circ} \mathrm{S}$ & 29.2 & 349 & 30.33 & 0.62 & 26.18 & 5.24 \\
\hline SCS_4 & $111.47^{\circ} \mathrm{E}$ & $9.25^{\circ} \mathrm{N}$ & 30.5 & 470 & 40.88 & 0.55 & 35.39 & 4.88 \\
\hline SCS_6 & $112.52^{\circ} \mathrm{E}$ & $12.78^{\circ} \mathrm{N}$ & 30.0 & 380 & 33.03 & 0.49 & 31.09 & 4.22 \\
\hline SCS_7 & $113.25^{\circ} \mathrm{E}$ & $15.17^{\circ} \mathrm{N}$ & 29.6 & 379 & 32.95 & 0.54 & 30.76 & 4.63 \\
\hline SCS_8 & $114.20^{\circ} \mathrm{E}$ & $17.17^{\circ} \mathrm{N}$ & 30.0 & 424 & 36.87 & 0.53 & 35.08 & 4.66 \\
\hline SCS_9 & $115.45^{\circ} \mathrm{E}$ & $19.19^{\circ} \mathrm{N}$ & 30.9 & 323 & 28.07 & 0.52 & 27.58 & 4.32 \\
\hline
\end{tabular}
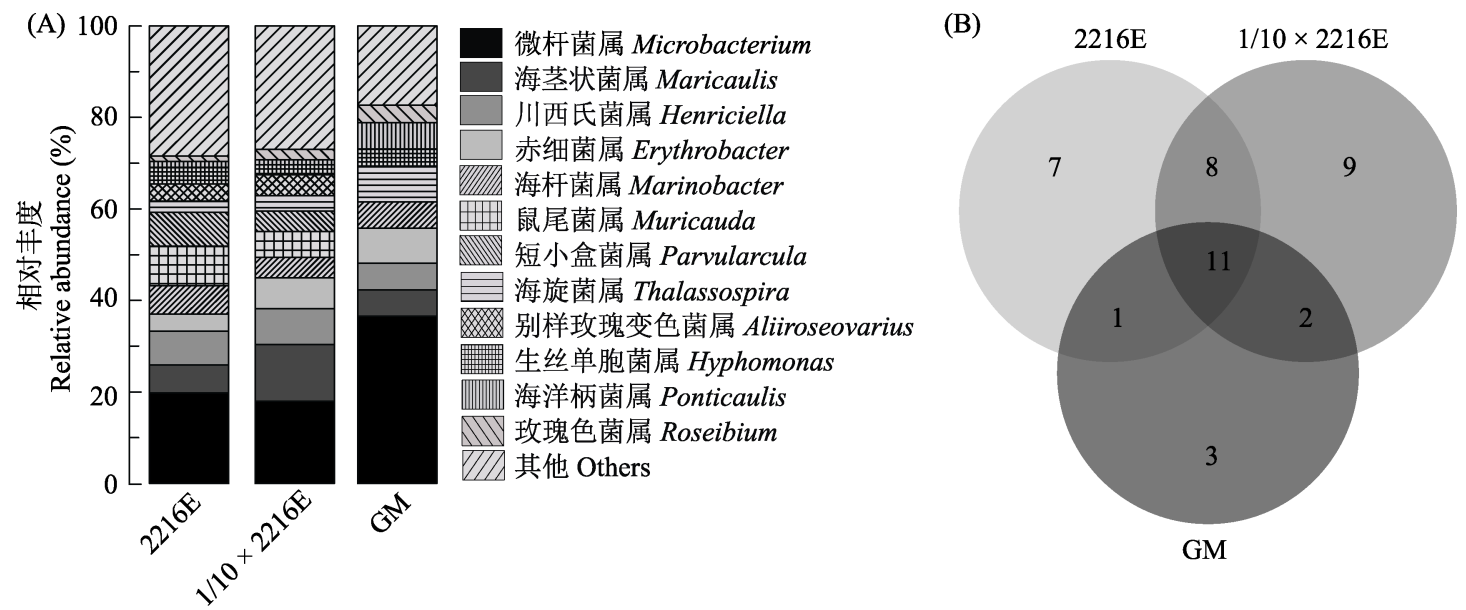

图3 三种不同培养基分离培养的(A)细菌多样性及(B)不同属的维恩分析。2216E, 2216E培养基; 1/10 × 2216E, 稀释10 倍的2216E培养基; GM，葡萄糖甘露糖培养基。

Fig. 3 Bacterial diversity and Venn analysis of differential genera isolated in three different media. 2216E, 2216E culture medium; $1 / 10 \times 2216 \mathrm{E}$, Diluted 10 times of $2216 \mathrm{E}$ culture medium; GM, Glucose-mannose culture medium.

$12.3 \% ; 1 / 10 \times 2216 \mathrm{E}$ 中分离出 25 株, 分属于 17 个 物种, 疑似新种率最高, 达 $19.1 \%$; GM培养出 8 株, 分属于7个物种，疑似新种率为 $13.5 \%$ 。

\section{3 海洋原位细菌群落多样性}

通过对 8 个表层海水样品中的细菌 $16 \mathrm{~S}$ rRNA 基因序列进行 Illumina测序, 发现不同样品中细 菌的 OTU 数目范围为 323-519, Margalef指数为 28.07-45.15 (表1)。在所有样品中, SCS_4样品的 $\mathrm{PD}$ 值最高, 为35.39。中印度洋样品中细菌 Shannon-Wiener指数为 5.67 , 显著高于南海西部 样品(4.54) $(P<0.05)$ 。此外, 中印度洋样品中 Pielou均匀度指数也显著高于南海西部样品 $(0.65$ vs. $0.53, P<0.05)$ 。
在分析的表层海水样品中, 共发现23个细菌 门。变形菌门相对丰度为 $72.2 \%$, 在细菌类群中占 绝对优势 (图4)。其中, $\alpha$-变形菌纲和 $\gamma$-变形菌纲是 丰度最高的变形菌, 而 $\beta$-变形菌纲与 $\delta$-变形菌纲 丰度较低。其他主要门类有拟杆菌门、蓝细菌门、 放线菌门与厚壁菌门，其丰度分别为 $15.3 \%$ 、 $5.5 \% 、 4.9 \%$ 和 $1.3 \%$ 。其中, 蓝细菌门类群在所有 样品中均占主要地位, 并以原绿球藻属 (Prochlorococcus) 与聚球藻属(Synechococcus) 为 主。在属水平, 共发现 531 个属。其中, 丰度最高 的属是嗜冷杆菌属(Psychrobacter), 占所有样品 中细菌类群的 $24.4 \%$ 。其次是盐单胞菌属 (Halomonas)和亚硫酸杆菌属(Sulfitobacter), 其相 


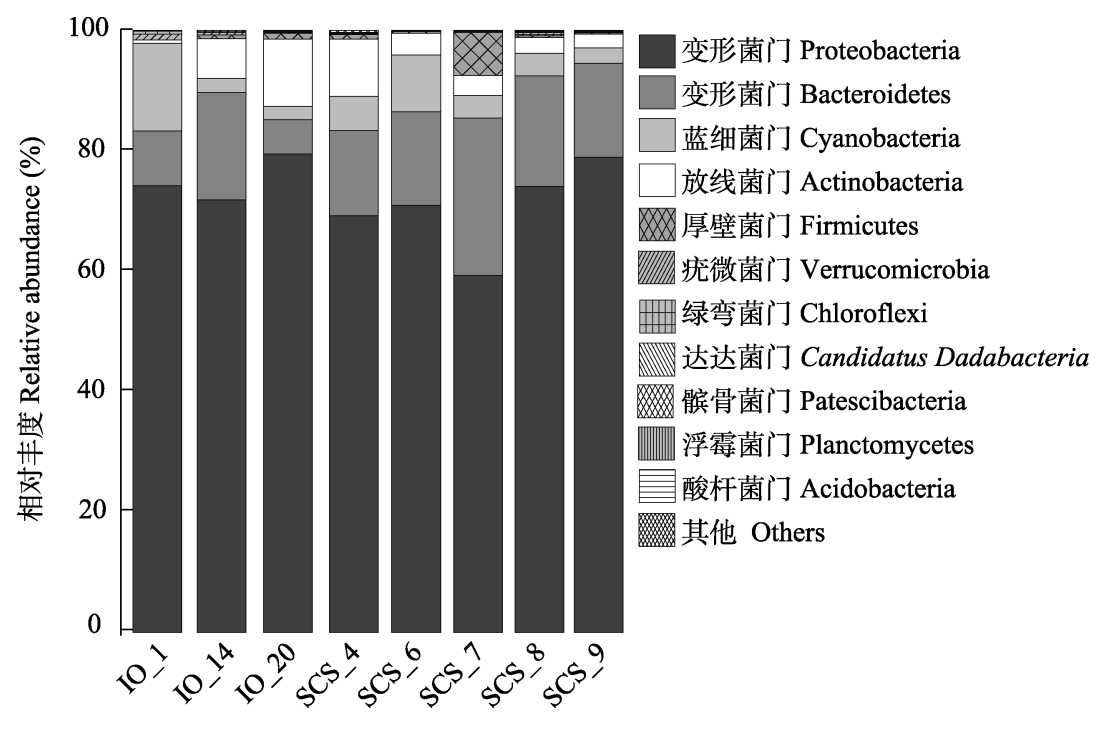

图4 中印度洋与南海西部表层海水中原位细菌在门水平上的组成分布

Fig. 4 In situ bacterial composition distributions at phylum level across the surface seawaters of the central Indian Ocean (IO) and the western South China Sea (SCS)

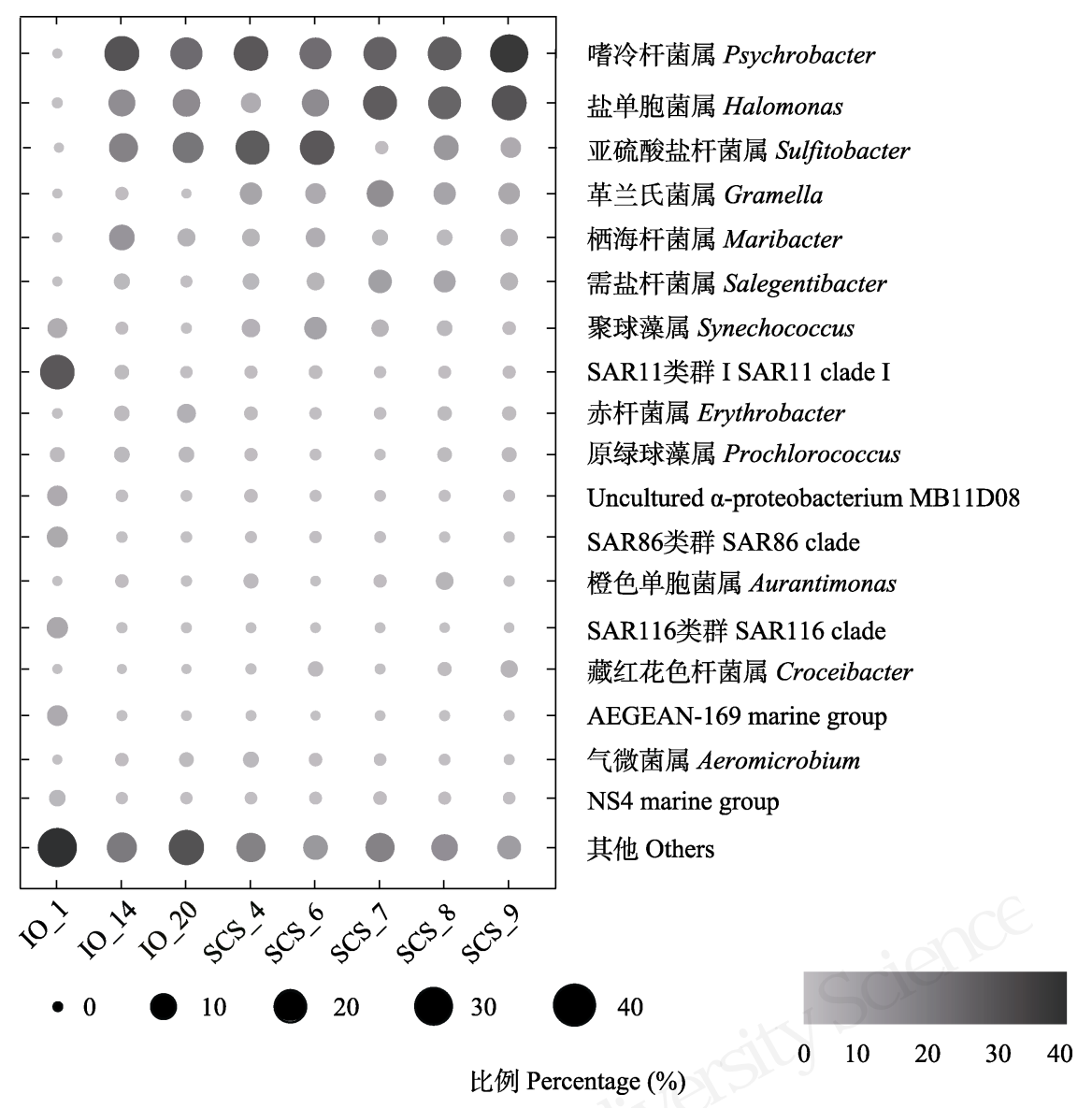

图 5 中印度洋与南海西部表层海水中原位细菌在属水平上的分布

Fig. 5 In situ bacterial composition distributions at genus level across the surface seawaters of the central Indian Ocean (IO) and the western South China Sea (SCS) 


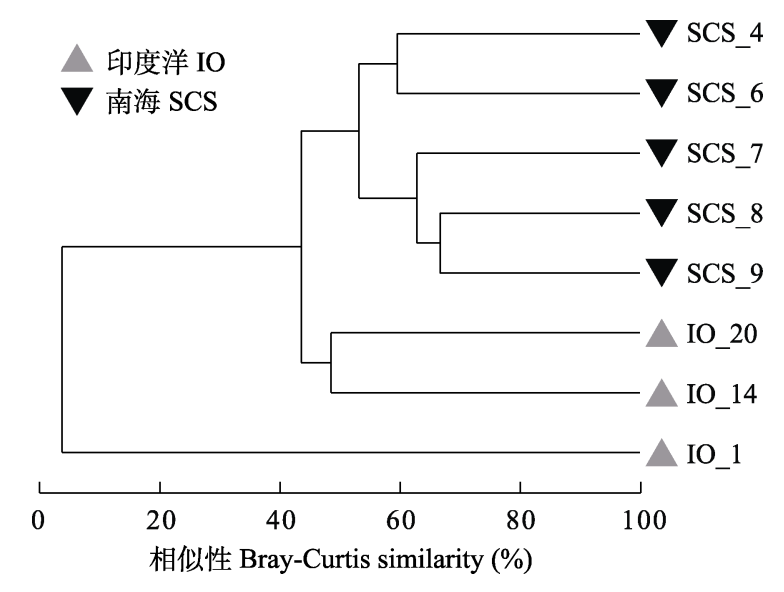

图 6 基于 Bray-Curtis 相似性的中印度洋及南海西部表 层海水中 ASV 聚类分析

Fig. 6 The cluster dendrogram analysis based on Bray-Curtis similarity of ASVs in the surface seawaters of the central Indian Ocean (IO) and the western South China Sea (SCS)

对丰度分别为 $16.3 \%$ 和 $13.9 \%$ (图5)。值得注意的是, 在发现的SAR11类群中, $85 \%$ 的类群分布在中印度 洋。聚类分析显示, 中印度洋与南海西部的细菌类 群明显分成两大组 (图6)。与此结果相一致, ANOSIM分析显示, 中印度洋与南海西部表层细菌 类群的 $R$ 值是 $0.74(P=0.018)$ 。相对于南海西部不同 站位的细菌群落, 中印度洋表层海水不同站位之间 的细菌群落相似性更低。

\section{3 讨论}

\section{1 表层海水可培养优势细菌类群}

海洋微生物在复杂有机物的矿化过程中发挥 重要作用(Louca et al, 2016)。本研究共采集了8个表 层海水样品, 完成了 275 株海洋细菌的分离纯化及 鉴定分析。这些可培养细菌分属于49属75种, 所获 得的可培养细菌种类远多于以往南海水体中获得 的可培养细菌(6-7属) (Zhuang et al, 2020)。与本研 究优势门类为变形菌门的结果不同, 先前研究报道 认为南海沉积物中优势门类为放线菌门(Liu et al, 2014b), 我们推测可能是由于水体与沉积物生境不 同及培养条件不同导致。在所有可培养海洋细菌中, $\alpha$-变形菌类群相对丰度最高(135株，49.1\%), 其中, 获得纯培养频率最高的是赤杆菌属, 共发现 4 个种 17 株菌。以往研究报道, 多数可培养赤杆菌是从浅 层海水中获得(Yoon et al, 2004), 可进行光合作用, 是海洋初级生产力的重要组成部分(Koblízek et al,
2003)。作为本研究中第二大优势类群 (59株, $21.5 \%$ ), 放线菌门仅包含 3 个属, 远远少于 Goodfellow和Fiedler (2010)在海洋环境中发现的 放线菌共 50 个属。在发现的拟杆菌门类群中, 所 有 25 株菌均为黄杆菌纲与噬纤维菌纲类群, 其在 南大洋表层海水中所占比例高达 $72 \%$ (Glöckner et al, 1999), 它们可以水解碳水化合物以及蛋白 质等含氮有机物 (Qin et al, 2010), 为海洋中 SAR11类群和 $\gamma$-变形杆菌的生长提供营养 (Williams et al, 2013)。

\section{2 不同培养条件下细菌分布特征与新颖性}

本研究采用3种不同营养类型与浓度的培养基 对表层海水细菌进行纯化培养。结果表明, 与天然 培养基 $(2216 \mathrm{E}$ 和 $1 / 10 \times 2216 \mathrm{E})$ 相比,合成培养基 (GM)未篮选出拟杆菌门类群。大多数拟杆菌可以产 生多种胞外降解酶(Qin et al, 2010), 而酶的合成与 分泌需要大量的资源, 特别是氮的投入(Frankena et al, 1988)。我们推测该类群需要更多类型的营养物 质来供给自身代谢需要, 因此很难在单一营养的 $\mathrm{GM}$ 培养基中生长。然而, 本研究中分离的芽孢杆菌 只在 $\mathrm{GM}$ 培养基上生长, 推测与其可以形成孢子来 抵御营养成分单一等不良环境的特性有关(Liu et al, 2014b)。

不同营养浓度梯度培养结果显示, 2216E培养 的细菌数目与种类略低于 $1 / 10 \times 2216 \mathrm{E}$ (数目: 81 株 vs. 89 株; 种类: 27 属 vs. 30 属)。2种培养基上可培 养细菌组成结构也显著不同, 分别有 8 与 11 个属只 在 $2216 \mathrm{E}$ 与 $1 / 10 \times 2216 \mathrm{E}$ 培养基上分离得到, 这可能 与培养菌株的营养浓度有关(Li et al, 2021)。之前的 研究表明, 常规的海洋细菌培养基的营养浓度远高 于海洋细菌的生长环境, 比较适合生长速度快的细 菌, 对于生长速度慢的细菌可能有抑制作用 (Zhuang et al, 2020)。例如, Schut等(1993)发现部分 海洋细菌仅能在含 $10 \mathrm{mg} / \mathrm{L}$ 碳浓度的培养基上形成 菌落。因此, 推测寡营养培养可以提高细菌的可培 养率, 同时增加细菌群落的多样性(Zhuang et al, 2020)。

研究共分离培养出 26 株可代表新分类单元的 菌株, 疑似新种率为 $18.2 \%$, 分属于 $3 门 4$ 纲 7 目 10 科 23属, 以 $\alpha$-变形菌类群为主。其中, Parvularcula sp. SbO06-11与Muricauda sp. SbO07-10的多相分类鉴 
定工作已经全部完成(Dang et al, 2019; Sun et al, 2019)。进一步, $1 / 10 \times 2216 \mathrm{E}$ 与 GM培养基获得可代 表新分类单元新型菌株比例高于 $2216 \mathrm{E}$ 培养基。因 此, 在远洋海域可培养细菌样品的采集时, 可通过 葟营养培养与改变营养类型来获得更丰富的可培 养微生物资源。

\section{3 海洋原位细菌群落的结构与多样性}

借助于高通量测序技术, 我们检测到中印度洋 与南海西部表层海水原位细菌优势门类为变形菌 门、拟杆菌门、蓝细菌门和放线菌门, 这与先前的 研究结果相符(Wang et al, 2016; Zhang et al, 2018)。 然而, 我们发现中印度洋与南海西部表层海水中原 位细菌群落结构显著不同 $(P<0.05)$ 。与南海西部相 比, 中印度洋表层海水中放线菌门相对丰度较高, 而厚壁菌门相对丰度较低(图4), 该结果与之前的 文献报道结果一致(Wang et al, 2016; Yu et al, 2019)。放线菌在海洋中广泛存在, 可以产生大量的 活性次级代谢产物, 在海洋有机物质降解过程中发 挥着重要作用( Li et al, 2012), 被普遍认为是海洋药 物开发和生物活性物质的重要微生物来源(Bull et al, 2005), 根据本研究结果推测中印度洋表层海水 中蕴含着更为丰富的放线菌及相关活性代谢产物 资源。

中印度洋与南海西部表层海水原位细菌除了 在门水平存在差异, 在属水平上也有较大差异。相 比于南海西部, 中印度洋表层海水中亚硫酸杆菌属 相对丰度较高, 而嗜冷杆菌属和盐单孢属相对丰度 则较低(图5)。先前有研究者指出亚硫酸杆菌属的细 菌可能参与海洋的硫循环(Ivanova et al, 2004), 并 且与海洋原油的生物降解密切相关 (Brakstad et al, 2005), 在维持海洋生态稳定性方面发挥重要作用。 而啫冷杆菌属和盐单孢属则具有特殊的生理机制 可以适应较为极端的环境。中印度洋与南海西部表 层海水中原位细菌群落表现出的差异, 推测可能与 洋流或原位环境影响有关(Li et al, 2018)。

\section{ORCID}

夏呈强 (D) https://orcid.org/0000-0001-7439-7280

\section{参考文献}

Brakstad OG, Lødeng AGG (2005) Microbial diversity during biodegradation of crude oil in seawater from the North Sea. Microbial Ecology, 49, 94-103.
Bryant JA, Aylward FO, Eppley JM, Karl DM, Church MJ, DeLong EF (2016) Wind and sunlight shape microbial diversity in surface waters of the North Pacific Subtropical Gyre. The ISME Journal, 10, 1308-1322.

Bull AT, Stach JEM, Ward AC, Goodfellow M (2005) Marine actinobacteria: Perspectives, challenges, future directions. Antonie Van Leeuwenhoek, 87, 65-79.

Caporaso JG, Kuczynski J, Stombaugh J, Bittinger K, Bushman FD, Costello EK, Fierer N, Peña AG, Goodrich JK, Gordon JI, Huttley GA, Kelley ST, Knights D, Koenig JE, Ley R, Lozupone CA, McDonald D, Muegge BD, Pirrung M, Reeder J, Sevinsky JR, Turnbaugh PJ, Walters WA, Widmann J, Yatsunenko T, Zaneveld J, Knight R (2010) QIIME allows analysis of high-throughput community sequencing data. Nature Methods, 7, 335-336.

Clarke KR (1993) Non-parametric multivariate analysis of changes in community structure. Australian Journal of Ecology, 18, 117-143.

Curson ARJ, Todd JD, Sullivan MJ, Johnston AWB (2011) Catabolism of dimethylsulphoniopropionate: Microorganisms, enzymes and genes. Nature Reviews Microbiology, 9, 849-859.

Dang YR, Sun YY, Sun LL, Yuan XX, Li Y, Qin QL, Chen XL, Zhang YZ, Shi M, Zhang XY (2019) Muricauda nanhaiensis sp. nov., isolated from seawater of the South China Sea. International Journal of Systematic and Evolutionary Microbiology, 69, 2089-2094.

Du R, Yu M, Cheng JG, Zhang JJ, Tian XR, Zhang XH (2019) Diversity and sulfur oxidation characteristics of cultivable sulfur oxidizing bacteria in hydrothermal fields of Okinawa Trough. Acta Microbiologica Sinica, 59, 1036-1049. (in Chinese with English abstract) [杜瑞, 于敏, 程景广, 张静 静, 田晓荣, 张晓华 (2019) 冲绳海槽热液区可培养硫氧 化细菌多样性及其硫氧化特性. 微生物学报, 59, 1036-1049.]

Frankena J, van Verseveld HW, Stouthamer AH (1988) Substrate and energy costs of the production of exocellular enzymes by Bacillus licheniformis. Biotechnology and Bioengineering, 32, 803-812.

Gauch HG, Scruggs WM (1980) Variants of Bray-Curtis polar ordination. Vegetatio, 40, 147-153.

Glöckner FO, Fuchs BM, Amann R (1999) Bacterioplankton compositions of lakes and oceans: A first comparison based on fluorescence in situ hybridization. Applied and Environmental Microbiology, 65, 3721-3726.

Goodfellow M, Fiedler HP (2010) A guide to successful bioprospecting: Informed by actinobacterial systematics. Antonie Van Leeuwenhoek, 98, 119-142.

Hanson CA, Fuhrman JA, Horner-Devine MC, Martiny JBH (2012) Beyond biogeographic patterns: Processes shaping the microbial landscape. Nature Reviews Microbiology, 10, 497-506.

Ivanova EP, Gorshkova NM, Sawabe T, Zhukova NV, Hayashi 2022年 | 30卷 | 1期 | 21407| 第8页 
K, Kurilenko VV, Alexeeva Y, Buljan V, Nicolau DV, Mikhailov VV, Christen R (2004) Sulfitobacter delicatus sp. nov. and Sulfitobacter dubius sp. nov., respectively from a starfish (Stellaster equestris) and sea grass (Zostera marina). International Journal of Systematic and Evolutionary Microbiology, 54, 475-480.

Keylock CJ (2005) Simpson diversity and the Shannon-Wiener index as special cases of a generalized entropy. Oikos, 109, 203-207.

Kobližek M, Béjà $\mathrm{O}$, Bidigare RR, Christensen S, Benitez-Nelson B, Vetriani C, Kolber MK, Falkowski PG, Kolber ZS (2003) Isolation and characterization of Erythrobacter sp. strains from the upper ocean. Archives of Microbiology, 180, 327-338.

Li HY, Chen MX, Jiao NZ (2012) The community composition of bacterioplankton at typical station in the Changjiang Estuary. Acta Oceanologica Sinica, 34, 183-188. (in Chinese) [李和阳, 陈明霞, 焦念志 (2012) 长江口典型站 位浮游细菌类群的组成特征研究. 海洋学报(中文版), 34, 183-188.]

Li Y, Sun LL, Sun ML, Su HN, Zhang XY, Xie BB, Chen XL, Zhang YZ, Qin QL (2018) Vertical and horizontal biogeographic patterns and major factors affecting bacterial communities in the open South China Sea. Scientific Reports, 8, 8800 .

Li Y, Wang ZB, Zhang XY, Dang YR, Sun LL, Zhang WP, Fu HH, Yang GP, Wang M, McMinn A, Chen XL, Chen Y, Wang S, Zhang YZ, Qin QL (2021) Experimental evidence for long-term coexistence of copiotrophic and oligotrophic bacteria in pelagic surface seawater. Environmental Microbiology, 23, 1162-1173.

Lin Y, Liu RH, Zhou S, Zhu XY, Wang JY, Zhang XH (2021) Diversity of culturable heterotrophic bacteria from sediments of the Mariana Trench and their ability to degrade dimethylsulfoniopropionate (DMSP). Acta Microbiologica Sinica, 61, 828-844. (in Chinese with English abstract) [林 钰, 刘荣华, 周顺, 朱晓雨, 王金燕, 张晓华 (2021) 马 里亚纳海沟沉积物可培养异养细菌的多样性及其DMSP 降解能力. 微生物学报, 61, 828-844.]

Liu JW, Yang HM, Zhao MX, Zhang XH (2014a) Spatial distribution patterns of benthic microbial communities along the Pearl Estuary, China. Systematic and Applied Microbiology, 37, 578-589.

Liu YJ, Tian XP, Huang XF, Long LJ, Zhang S (2014b) Diversity of cultivable bacteria isolated from marine sediment environments in South China Sea. Microbiology China, 41, 661-673. (in Chinese with English abstract) [刘 玉娟, 田新朋, 黄小芳, 龙丽娟, 张偲 (2014) 中国南海 沉积环境可培养细菌多样性研究. 微生物学通报, 41, 661-673.]

Louca S, Parfrey LW, Doebeli M (2016) Decoupling function and taxonomy in the global ocean microbiome. Science, $353,1272-1277$.
Qin QL, Zhang XY, Wang XM, Liu GM, Chen XL, Xie BB, Dang HY, Zhou BC, Yu J, Zhang YZ (2010) The complete genome of Zunongwangia profunda SM-A87 reveals its adaptation to the deep-sea environment and ecological role in sedimentary organic nitrogen degradation. BMC Genomics, 11, 247.

Qu TD, Girton JB, Whitehead JA (2006) Deepwater overflow through Luzon Strait. Journal of Geophysical Research Atmospheres, 111, C01002.

R Core Team (2016) R: A Language and Environment for Statistical Computing. $\mathrm{R}$ Foundation for Statistical Computing, Vienna, Austria.

Rappé MS, Giovannoni SJ (2003) The uncultured microbial majority. Annual Review of Microbiology, 57, 369-394.

Salazar G, Cornejo-Castillo FM, Benítez-Barrios V, FraileNuez E, Álvarez-Salgado XA, Duarte CM, Gasol JM, Acinas SG (2016) Global diversity and biogeography of deep-sea pelagic prokaryotes. The ISME Journal, 10, 596608.

Schut F, de Vries EJ, Gottschal JC, Robertson BR, Harder W, Prins RA, Button DK (1993) Isolation of typical marine bacteria by dilution culture: Growth, maintenance, and characteristics of isolates under laboratory conditions. Applied and Environmental Microbiology, 59, 2150-2160.

Su J, Ming HX, Chen QR, Zhang CX, Guan DM, Fan JF (2020) Analysis on bacterial diversity in Nansha deep-sea sediments. Journal of Biology, 37(1), 50-53. (in Chinese with English abstract) [苏洁, 明红霞, 陈泉睿, 张春金鍑, 关道明, 䐆景凤 (2020) 南沙海区深海沉积物中细菌多 样性分析. 生物学杂志, 37(1), 50-53.]

Sun LL, Dang YR, Li Y, Qin QL, Su HN, Li PY, Chen XL, Zhang YZ, Zhang XY (2019) Parvularcula marina sp. nov., isolated from surface water of the South China Sea, and emended description of the genus Parvularcula. International Journal of Systematic and Evolutionary Microbiology, 69, 2571-2576.

Wang J, Kan JJ, Borecki L, Zhang XD, Wang DX, Sun J (2016) A snapshot on spatial and vertical distribution of bacterial communities in the eastern Indian Ocean. Acta Oceanologica Sinica, 35, 85-93.

Wang XW, Liu ZY, Peng SQ (2017) Impact of tidal mixing on water mass transformation and circulation in the South China Sea. Journal of Physical Oceanography, 47, 419-432.

Williams TJ, Wilkins D, Long E, Evans F, DeMaere MZ, Raftery MJ, Cavicchioli R (2013) The role of planktonic Flavobacteria in processing algal organic matter in coastal East Antarctica revealed using metagenomics and metaproteomics. Environmental Microbiology, 15, 13021317.

Yoon JH, Kang KH, Oh TK, Park YH (2004) Erythrobacter aquimaris sp. nov., isolated from sea water of a tidal flat of the Yellow Sea in Korea. International Journal of Systematic and Evolutionary Microbiology, 54, 1981-1985. 
Yu QW, Hu LQ, Li F, Yi XX, Gao CH (2015) Diversity and biotoxicity of cultivable marine bacteria isolated from deep-sea sediment of the South China Sea. Journal of Southern Agriculture, 46, 2203-2208. (in Chinese with English abstract) [于清武, 胡丽琴, 李菲, 易湘茜, 高程海 (2015) 南海深海沉积物可培养细菌多样性及其生物毒性 分析. 南方农业学报, 46, 2203-2208.]

Yu SX, Wang YC, Li JL, Pang YL, Qin S (2019) Comparative analysis of bacteria communities from water and surface sediment in northern South China Sea. Advances in Marine Science, 37(1), 102-114. (in Chinese with English abstract) [于淑贤, 王寅初, 李佳霖, 庞云龙, 秦松 (2019) 南海北 部水层间及沉积表层细菌群落的比较分析. 海洋科学进 展, 37(1), 102-114.]

Zhang Y, Li J, Cheng XH, Luo YF, Mai ZM, Zhang S (2018)
Community differentiation of bacterioplankton in the epipelagic layer in the South China Sea. Ecology and Evolution, 8, 4932-4948.

Zhuang K, Hu XJ, Cao YC, Xu YN, Zhang JS, Wen GL (2020) Bacterial community structure and its utilization characteristics of carbon sources in water of South China Sea under different low-nutrient culture conditions. Microbiology China, 47, 2697-2710. (in Chinese with English abstract) [庄康, 胡晓娟, 曹显成, 许云娜, 张建 设, 文国樑 (2020) 不同寡营养培养条件下南海水体细 菌群落结构及其对碳源的利用特征. 微生物学通报, 47 , 2697-2710.]

(责任编委: 东秀珠 责任编辑: 李会丽)

\section{附录 Supplementary Material}

附录1 中印度洋及南海西部研究站位示意图

Appendix 1 The research stations in the central Indian Ocean and the western South China Sea https://www.biodiversity-science.net/fileup/PDF/2021407-1.pdf

\section{附录2 基于16S rRNA基因序列构建中印度洋及南海西部表层海水可培养细菌的邻近系统发育树}

Appendix 2 Neighbor-joining phylogenetic tree of cultivable bacteria isolated from the surface seawaters of the central Indian Ocean and the western South China Sea based on 16S rRNA gene sequences

https://www.biodiversity-science.net/fileup/PDF/2021407-2.pdf

附录3 中印度洋和南海西部表层海水不同属的维恩分析

Appendix 3 Venn analysis of differential genera in the surface seawaters of the central Indian Ocean and the western South China Sea

https://www.biodiversity-science.net/fileup/PDF/2021407-3.pdf

附录4 印度洋及南海表层海水中潜在新型菌株

Appendix 4 Potential novel taxa of bacteria in the surface seawater of the central Indian Ocean and the western South China Sea https://www.biodiversity-science.net/fileup/PDF/2021407-4.pdf 
夏呈强, 李毅, 党延茹, 察倩倩, 贺晓艳, 秦启龙 (2022) 中印度洋与南海西部表层海水细菌多样性. 生物多样性, 30, 21407. https://www.biodiversity-science.net/CN/10.17520/biods.2021407

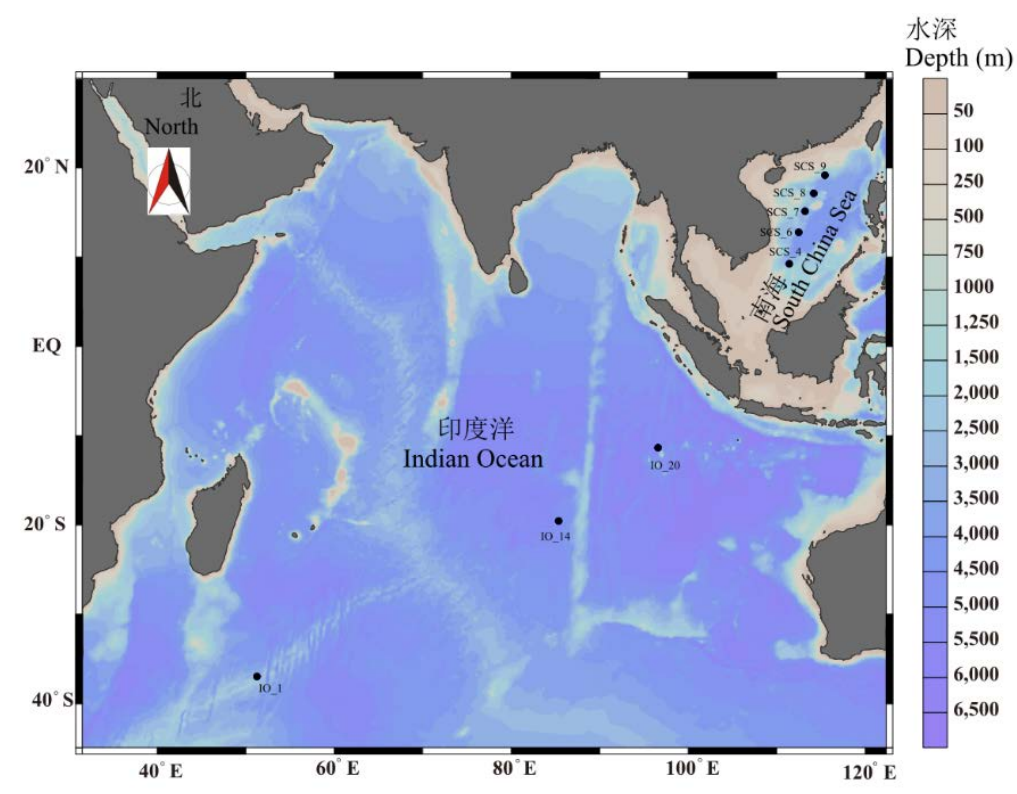

附录 1 中印度洋及南海西部研究站位示意图

Appendix 1 The research stations in the central Indian Ocean and the western South China Sea 
夏呈强, 李毅, 党延茹, 察倩倩, 贺晓艳, 秦启龙 (2022) 中印度洋与南海西部表层海水细菌多样性. 生物多样性, 30, 21407. https://www.biodiversity-science.net/CN/10.17520/biods.2021407

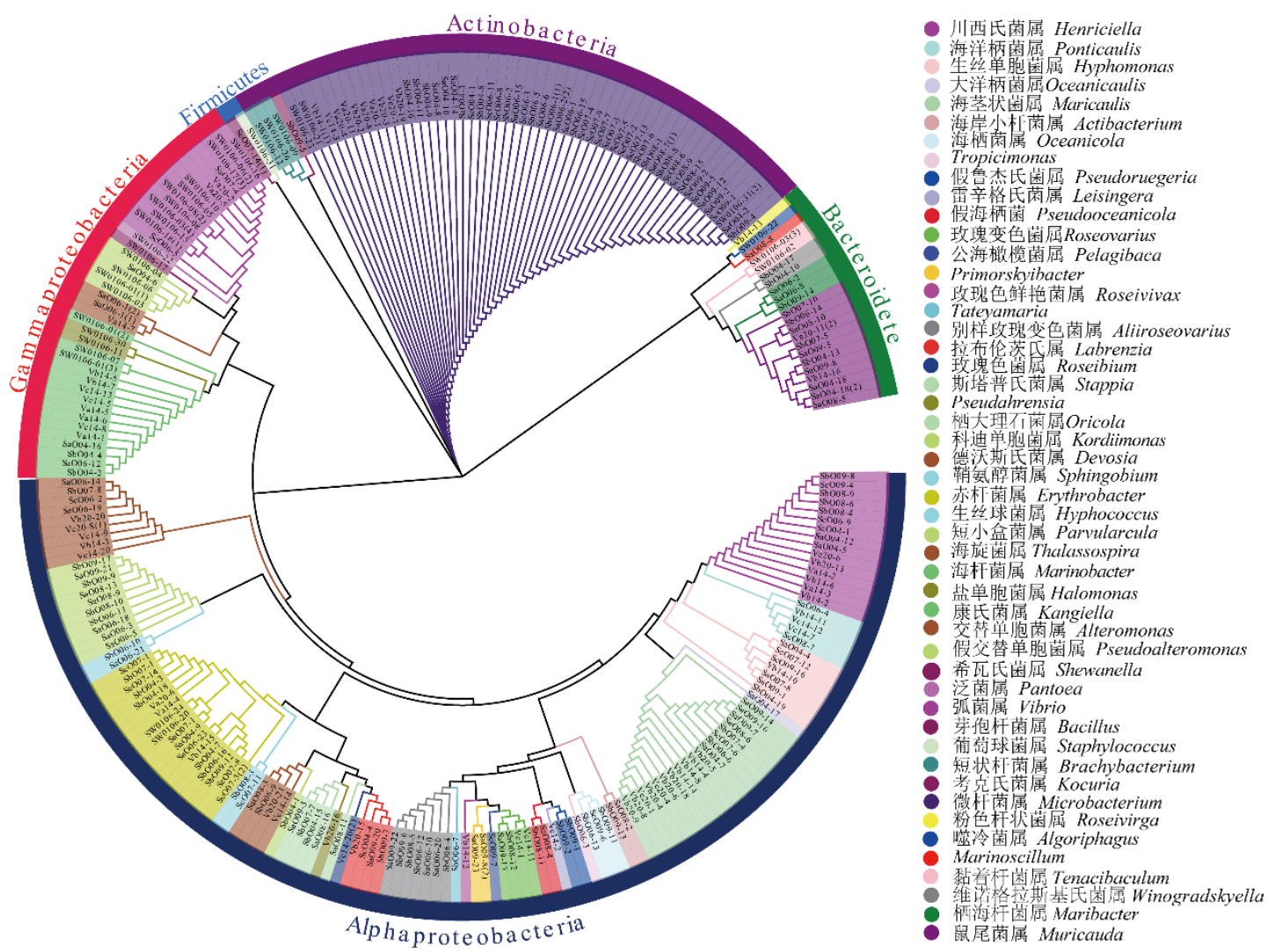

附录2 基于16S rRNA基因序列构建中印度洋及南海西部表层海水可培养细菌的邻近系统发育树

Appendix 2 Neighbor-joining phylogenetic tree of cultivable bacteria isolated from the surface seawaters of the central Indian Ocean and the western South China Sea based on 16S rRNA gene sequences 
夏呈强, 李毅, 党延茹, 察倩倩, 贺晓艳, 秦启龙 (2022) 中印度洋与南海西部表层海水细菌多样性. 生物多样性, 30, 21407. https://www.biodiversity-science.net/CN/10.17520/biods.2021407

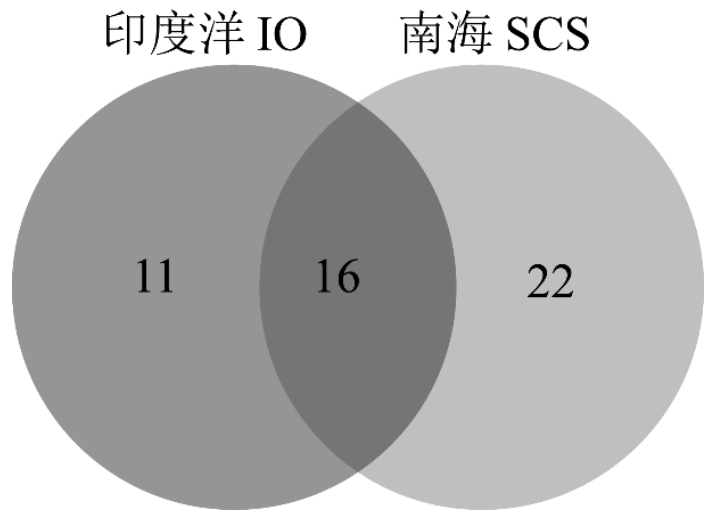

附录3 中印度洋和南海西部表层海水不同属的韦恩分析

Appendix 3 Venn analysis of differential genera in the surface seawaters of the central Indian Ocean and the western South China Sea 
夏呈强, 李毅, 党延茹, 察倩倩, 贺晓艳, 秦启龙 (2022) 中印度洋与南海西部表层海水细菌多样性. 生物多样性, 30, 21407. https://www.biodiversity-science.net/CN/10.17520/biods.2021407

附录4 印度洋及南海表层海水中潜在新型菌株

Appendix 4 Potential novel taxa of bacteria in the surface seawater of the central Indian Ocean and the western South China Sea

\begin{tabular}{|c|c|c|c|c|}
\hline 代表菌株 & 中文名称 & 相似菌株 & 相似度 & 登录号 \\
\hline Strain & Chinese name & Closest relatives & Similarity (\%) & Accession number \\
\hline \multirow[t]{2}{*}{ SaO09-8 } & 威廉港鼠尾菌 & Muricauda ruestringensis DSM & 98.63 & СР002999 \\
\hline & & 13258 & & \\
\hline ScO07-14 (1) & 婴儿芽胞杆菌 & Bacillus infantis NRRL B-14911 & 98.59 & AY706935 \\
\hline ScO09-6 & 海滨范尼尔菌 & Vannielia litorea DSM 29440 & 98.57 & jgi.1107645 \\
\hline $\mathrm{SaO06-4}$ & 深海海洋柄菌 & Ponticaulis profundi YC239 & 98.51 & MF039068 \\
\hline SbO04-7 & 普通钱培元菌 & Qipengyuania vulgaris 022 2-10 & 98.31 & AY706935 \\
\hline SbO07-7 & 解纤维素居海岸菌 & Oricola cellulosilytica CC-AMH-0 & 98.15 & KF582604 \\
\hline \multirow[t]{2}{*}{ SbO04-3 } & 南海赤杆菌 & Erythrobacter nanhaiensis & 98.15 & AEUE01000008 \\
\hline & & JLT1363 & & \\
\hline Vc14-20 & 碱蓬玫瑰色菌 & Roseibium suaedae DSM 22153 & 98.14 & jgi.1107719 \\
\hline $\mathrm{SaO06-23}$ & 海水钱培元菌 & Qipengyuania aquimaris SW-110 & 98.07 & AY461441 \\
\hline SbO08-12 & 印度洋玫瑰变色菌 & Roseovarius indicus B108 & 98.05 & LAXI01000023 \\
\hline SbO06-7 & 海螺立山菌 & Tateyamaria omphalii MKT107 & 97.87 & AB193438 \\
\hline Va14-7 & 白色交替单胞菌 & Alteromonas alba 190 & 97.72 & MG856904 \\
\hline SaO06-1 (1) & 大洋交替单胞菌 & Alteromonas oceani S35 & 97.69 & MF687202 \\
\hline SbO08-3 & 土壤新鞘氨醇菌 & Sphingobium soli THG-SQA7 & 97.67 & KM598233 \\
\hline ScO07-3 & 碱蓬赤杆菌 & Erythrobacter suaedae GH3-15 & 97.49 & MG905438 \\
\hline \multirow[t]{2}{*}{ Vc14-2 } & 雷辛格氏菌（加词 & Leisingera caerulea DSM & 97.38 & KI421513 \\
\hline & 待译) & 24564(T) & & \\
\hline $\mathrm{SaO} 08-2$ & 解脲海岸小杆菌 & Actibacterium ureilyticum LS-811 & 97.35 & NSBT01000007 \\
\hline \multirow[t]{2}{*}{ SbO09-2 } & 海水假鲁杰氏菌 & Pseudoruegeria aquimaris CECT & 97.11 & FWFQ01000052 \\
\hline & & 7680 & & \\
\hline SbO09-13 & 紫色小红卵菌 & Rhodovulum iodosum N1 & 96.76 & Y15011 \\
\hline SbO06-10 & 黄色生丝球菌 & Hyphococcus flavus HSF6 & 96.69 & KX418769 \\
\hline \multirow[t]{2}{*}{ SbO06-11 } & 百慕大短小盒菌 & Parvularcula bermudensis & 96.52 & AAMU01000003 \\
\hline & & HTCC2503 & & \\
\hline SbO06-3 & - & Silicimonas algicola KC90 & 95.36 & KU926270 \\
\hline SbO07-10 & - & Muricauda ochracea JGD-17 & 96.26 & MN908334 \\
\hline \multirow[t]{2}{*}{ SbO04-19 } & 大西洋生丝单胞菌 & Hyphomonas atlantica 22II1- & 95.20 & AWFH01000061 \\
\hline & & 22F38 & & \\
\hline Vb20-16 & - & Salaquimonas pukyongi RR3-28 & 95.02 & СР019044 \\
\hline SaO08-8 & - & Marinoscillum luteum SJP7 & 93.29 & HM161878 \\
\hline
\end{tabular}

